\title{
JeuTICE: An Arabic Serious Game to Enhance Mathematics Skills of Young Children
}

\author{
https://doi.org/10.3991/ijet.v14i22.11119 \\ Yassine Tazouti $\left({ }^{\square}\right)$ \\ Ibn Tofail University, Kenitra, Morocco \\ yassine.tazouti@gmail.com \\ Siham Boulaknadel \\ Royal Institute of Amazigh Culture, Rabat, Morocco \\ Youssef Fakhri \\ Ibn Tofail University, Kenitra, Morocco
}

\begin{abstract}
Serious games have become a much-discussed trend topic in recent years, as the concept promises higher productivity while increasing user satisfaction. In this paper we present JeuTICE an Arabic serious game project model for mathematics learning. this digital resource was approved by VAREN project and hosted at the portal TICE of Moroccan Education Ministry on open access for students and educators. this resource revealed a several additions targeted mathematics learning for students of the 5th and 6th primary school. The goal is to successfully transfer positive properties of digital games, such as motivation and commitment, to a different usage context. Potentially, this goal is achieved by focusing on user experience and integrating game elements into the consideration subject. JeuTICE was evaluated by GENIE program by a range of 60 students from different public Moroccan primary schools the result obtained are very satisfied to ensure the quality and usability of the serious game.
\end{abstract}

Keywords - Serious game, game-based leaning, game learning, mathematics learning, educational game.

\section{Introduction}

Designing a meaningful gamification levels is not a trivial task, as different competencies (IT, psychology, game design, didactics) are required and different actors should be involved [1]. First of all, the question arises as to which gamification elements would be eligible in principle in order to bring about productivity benefits for the learners. The diversity and complexity of different gamification approaches makes selection decisions for a successful assessment of the learners [2]. It is therefore important to consider at the outset to be achieved and specific processes and indicators are suitable to make progress measurable.

There are always many advantages to learn from serious games [3]. To increase engagement, learners can determine for himself which learning content is important to him and how intensively they want to learn it [4]. At school, teachers will set a certain pace when conveying new content, which is adequate for the majority of students. Not everyone can follow that pace. But with JEUTICE serious game, which contains tree 
minigames each one deals with a specific learning task (surfaces game, numbers game, measures game) the learner can determine the pace of learning for himself [5]. This gives the learner the opportunity to repeat some learning situations in a fun way as often as they like until they feel confident themselves [6].

Gamification elements of should be linked to appropriate processes [7]. If the mechanics behind the mathematics gamification approaches are dispersible or unknown, this can reduce the attractiveness to users [8]. If the assignment of rewards and status appears arbitrary, the motivation, the learning achieved goals will decrease, this effect can be so strong that the players have a rejection attitude of the game. For this reason, it is necessary to communicate clearly what mechanics are behind a particular element [9]. At the same time, rewards should be designed in such a way that they do not lead to undesirable learners' behaviors [10].

The desire for competition is the will to win, but it is also the manifestation of personal merit to establish some superiority over oneself or others [11,12]. Cooperation expresses the desire to belong to values of mutual help and sharing [13]. And by exploiting these points, competition and cooperation with the basic need for social recognition in pairs or with an identity group with an appropriate design methodology of the game, JEUTICE can increase the learner's engagement.

This serious game research project has been previously presented at the ICTA'15[14]. The learning environment currently covers school material from primary schools including 5th and 6th grade of primary school the above-mentioned subjects. Due to the broad target group as well as the varying school curricula within the Moroccan states, the platform is based on a didactic concept based on broader national and country-specific educational standards for the individual subjects.

\section{Related Work}

With the growing performance of serious games, extensive range of different solutions, many forms of learning have emerged such as Mohamed ahmed al khateeb research project [15]. an Arabic serious game for mathematics 4th grade learning which is clearly similar of JeuTICE scenario. This serious game composed of 9 level each level deals with a specific filed in student's mathematics textbook. Each contains an interactive environment with a background Music the player had to choose the correct answer without consuming time allowed to response on a specific question.

Another Arabic serious game called Afaneen [16] this serious game aims to enhance the Arabic spelling of student at the elementary and higher school, within the players can listen to a specific spelling and choose the corresponding word the game was being evaluated with some different methods in order to identify the usefulness of the game.

Super alpha [17] is another serious game for Arab alphabet learning designed for children with disabilities which contain seven different games drag and drop, shooting, flipping cards, painting, hangman, maze, puzzle game with matching distinguishing and recognizing mechanics. VREG [18] a mobile serious game with Arabic continent contains 3 games that covers multiples aspects and targets students between age 4 and 8 
years aiming to help them learn Arabic, English languages and mathematics the serious game was tested in two private schools.

Another project conducted by Sylke Vandercruysse [19] to produce a gamified environment for teaching mathematics to Prevocational students to practice related to reasoning problems and fulfil the psychological satisfaction.

\section{Game Elements}

As we mentioned the rollout of gamification elements must be carefully planned. Ideally, playful approaches are activated directly with the introduction of a game system, such as an internal communication platform, or when new components are activated, so that the playful aspect is present from the beginning. We designed a game interface "see figure 1" composed from several key learning element which are already defined by the game scenario we describe mainly:

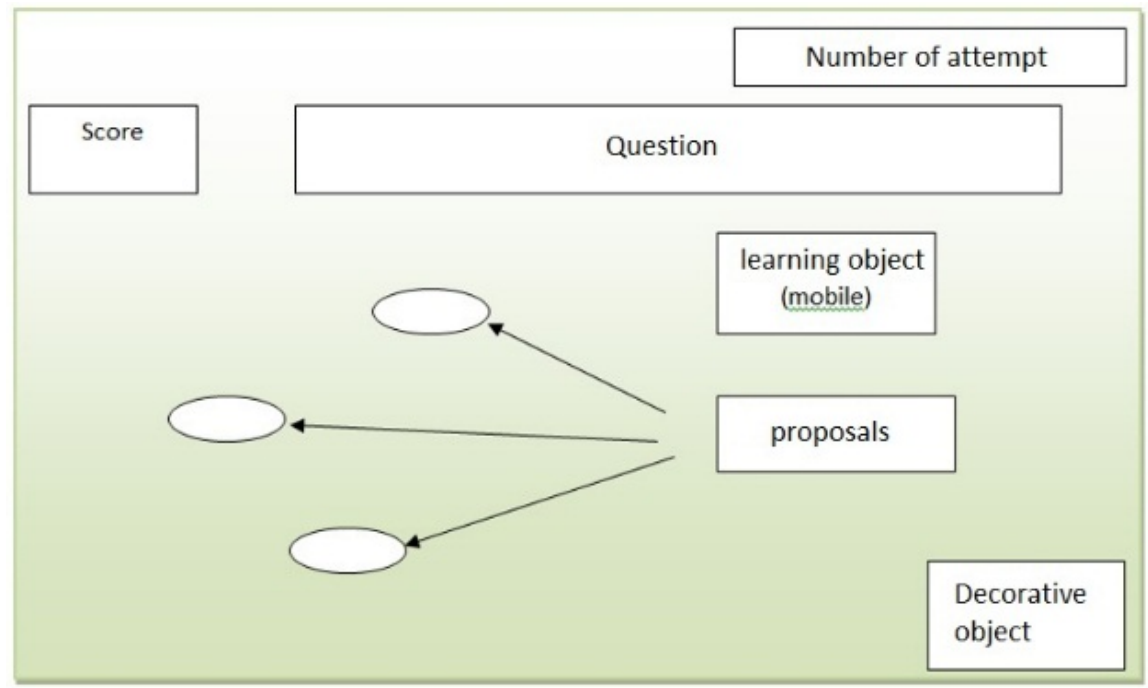

Fig. 1. Game Space Model

- Ball: (Proposals) contains random numbers or mathematical formula. Takes Bouncing trajectories in all directions by making reflections at the end of the visual plant. A single ball or several can hold the right value that fits our situation.

- Cursor: we replaced the original cursor to give the student a hunt point feel.

- Chasing airplane (Learning Object): That is the main character for the surface and number game is moving done using the movement keys (the arrows) and orientation follows the pointer of the mouse in a rotational way. Have the ability to generate directional small ball for each mouse click. 
- Helicopter (Learning Object): The main character for the measure game. Movement control of this object is done using the arrow keys to chase the correct answers in the blue balls.

- Number of attempts: An object presents on each scene. which illustrate the number of attempts that decrease for each collision between the aircraft generated fire balls or helicopter and an incorrect answer ball an attempt will be destroyed.

- Score: For each learning situation achieved. points will be adding to the score when the plane collides with a ball that contain the true answer, the ball will be destroyed and the counter goes to the next frame displaying an increment of 10 points for each situation achieved.

- Generated ball: Is an object for the purpose is to be generated at each right mouse click from a predefined place from the chasing airplane to the cursor pointer of the mouse.

- Scene scenery: Contains a static image. This is the only object that does not give access to any condition, action, or expression, but it is possible to test whether there is a collision between Decor objects and other objects.

\section{Gameplay}

When platform lunched, the user is asked after a game session for information about age, gender and school grade. These information's are used for a specific preselection of the learning evaluation material. Basically, JEUTICE offer a free game choice, each learning tasks can be chosen by the player.

While the learning modules are adaptable, one of three game tasks can be chosen which is adapted to the individual level of knowledge. modules are structured in such a way that at the beginning of the game session a problem situation is described, which has already solved before in mathematic course. For this, the player must acquire relevant knowledge in mathematic which enables problem solving.

Teacher's role is to observe the students and see if they are having difficulty to accomplish scene tasks. In response to the student's situation, the teacher should provide the necessary assistance, and reinterpret the gameplay and rules and rewards that are already implemented in the game "see figure 2".

Secondly, teachers shouldn't correct the students' mathematics errors at the process, this may undermine the evaluation progress and easily dampen the enthusiasm of the students. Conversely, teachers should praise and encourage students as much as possible. 


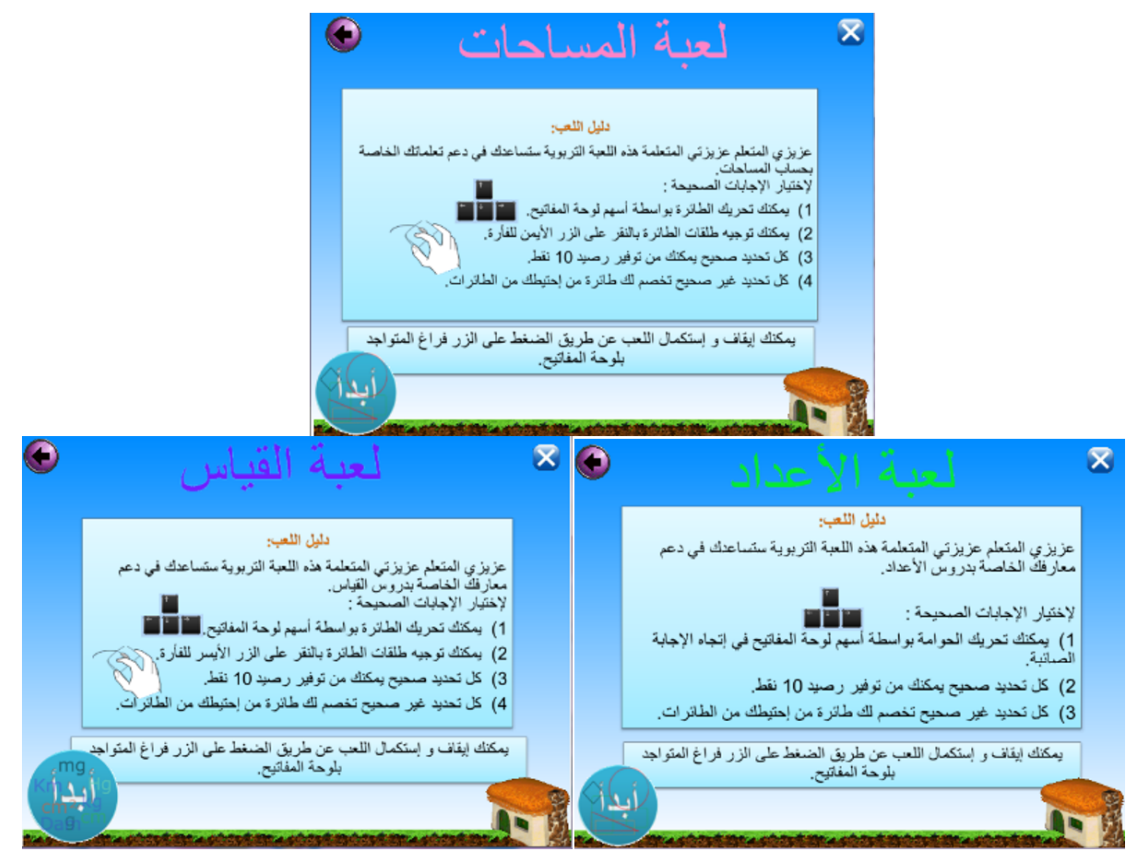

Fig. 2. Rewads and guidance of JEUTICE

The skill acquisition happens in a multiple pass of the gameplay cycle. The players perform a turn and receives a reaction. they assess the situations and decides the better choice. The set of rules by which the game works is by no means completely known from the start.

To ensure a learning effect, the game can be embedded in a didactically prepared learning situation. Instead certain skills are already acquired in the game itself, the game can provide an instruction to the players, which is intended to induce positive experiences among the participants, and is later evaluated. The game serves the motivation, the emotionalization and the self-experience. When planning corresponding learning situations, it must be remembered that the use of serious game is always required an additional expenditure of time compared to traditional knowledge transfer without such involvement-inducing elements.

In the three games each learning situation starts with a discount of 5-second to give players the time needed to identify the true answers for a question that presented randomly at the top of each game scene. for each right answer, proposals balls speed movement and questions complexity increase which presents a linear augmented variation of challenge degree. When the number of attempts is consumed the players must fills out a form to record obtained data and rank the player in a leader board to increase the challenge "see figure 3". The focus here is that teaching and learning methods used in games should be transferred into the lifeworld outside of games to increase the learning challenge and students' interest. These Playlists theories are developed through an analyst of gamification elements combining them with the learning principles from mathematic textbook. 


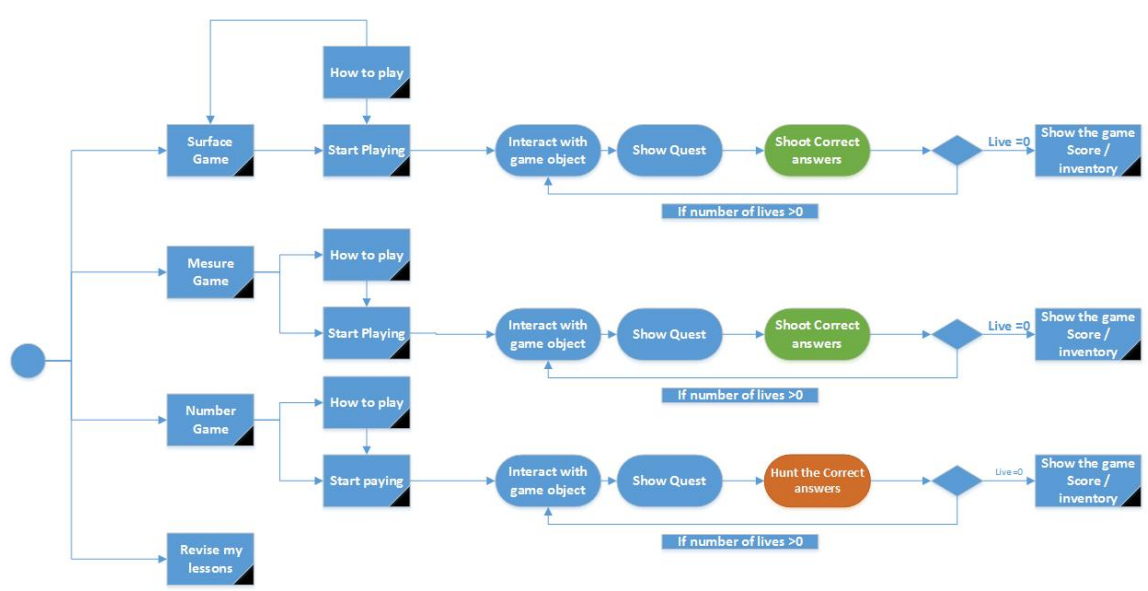

Fig. 3. Game Play process diagram

Feedbacks are made as remediation course "see figure 4". Players act, and they also accept their choses, taking the risks and consequences, and assuming what they do, which is essential. Nevertheless, feedbacks are not just a reinforcement information [20] used for the design of JEUTICE. The game thus offers students a space of freedom for decision-making but it also provides information on the consequences of the choices made. When students realize that points are being taken away because of an ignorant decision, they start see what they can do to earn points back. Returns are made possible by the fact that the teacher constantly collects information on what the player is doing and therefore on his ability to respect the rules of the class life. It is always possible to progress by performing an action to gain new points. These negative feedbacks have a priori consequences, that they do not alter the competence sense of students, while positive feedback such as point gains or progression in the rank table are likely to enhance this sense of competence which is a key dimension of school motivation.

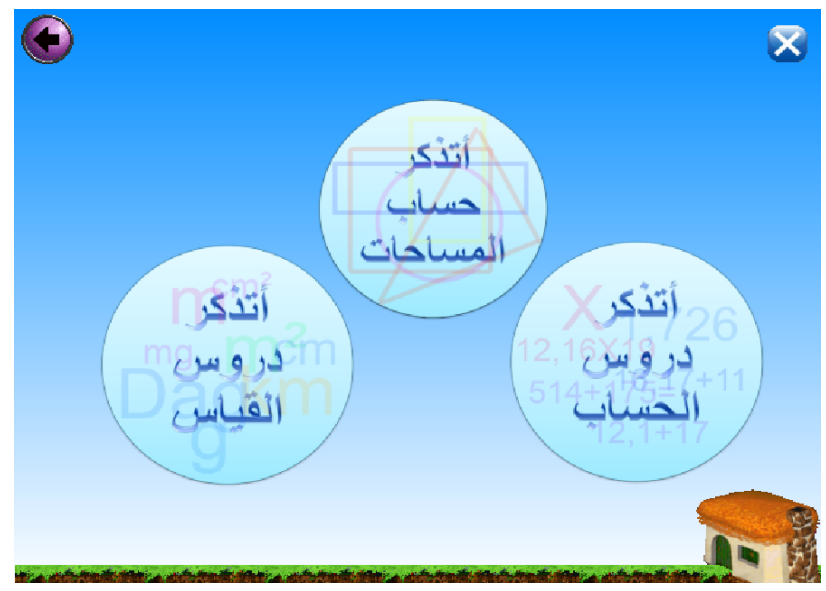

Fig. 4. Basic rules of mathematics 


\subsection{Learning objectives}

Numbers game: a serious game environment that deals with calculates learning principles. The player must read the questions at the top of the game scene, locate the correct answers and move the helicopter by using directional keys "see figure 5" to collect the Balls which represents the correct answers. The player must avoid collisions with the wrong answers which reduce the number of attempts. The game mainly deals with these learning objectives:

- Identify integers and decimals

- Determine the multiples of 5 and 3

- Determine the divisors of 4 and 9

- Calculate and reduce the sum of two decimals

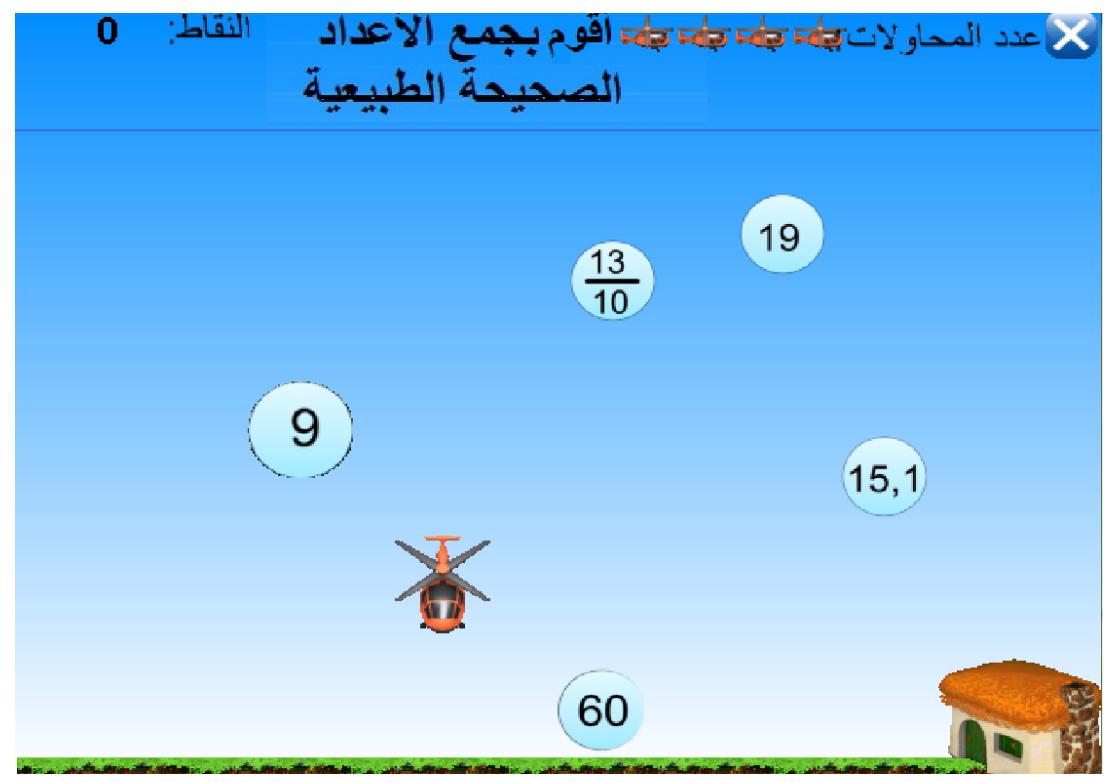

Fig. 5. Numbers Game Scene view

Surfaces Game deals with the geometric activities. The players had as prerequisite mathematics lesson about rules of perimeters and surfaces calculating of usual forms. In this situation, the player's role is to read the questions carefully. To properly manipulate the mouse, through arrows keys the player can chase and targeted the balls "see figure 6" that contain true answers and avoid shooting the balls that contains incorrect answers. The game target these learning objectives:

- Calculate the area of a rectangle

- Calculate the area of a square

- Calculate the area of a triangle

- Calculate the area of a circle 
- Calculate the perimeter of a rectangle

- Calculate the perimeter of a square

- Calculate the perimeter of a triangle

- Calculate the perimeter of a circle

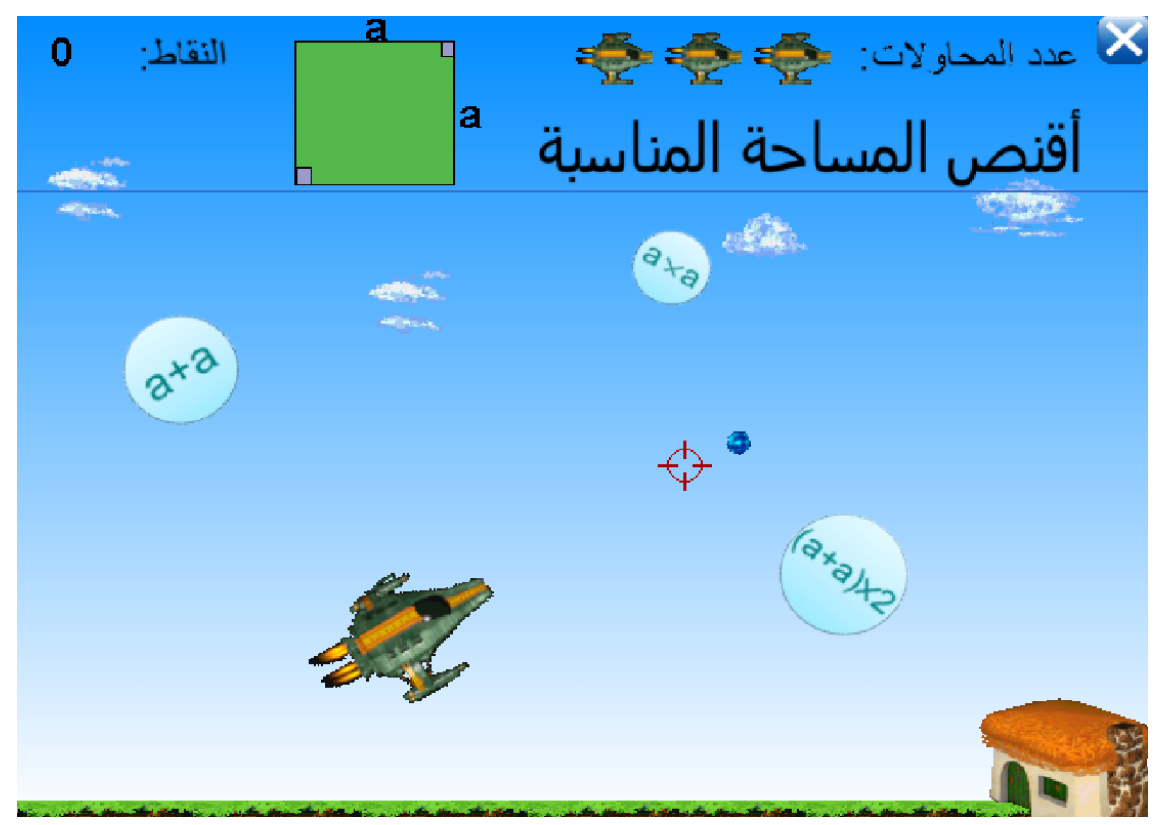

Fig. 6. Surfaces Game Scene view

The third game "Measures Game" presents measurement activities. The game scenario is same to surface game "see figure 7". The player must be able to know measurement length, masses, surfaces and volumes units, the player had as prerequisite knowledge these symbols units. We targeted in this game these learning objectives:

- Determine the fractions of gram

- Determine the multiples of gram

- Identify the units of mass

- Identify surface measurement units

- Identify length measurement units

- Determine the fractions of meter and square meter

- Determine the multiples of square meter

- Determine the fractions of cubic meter 


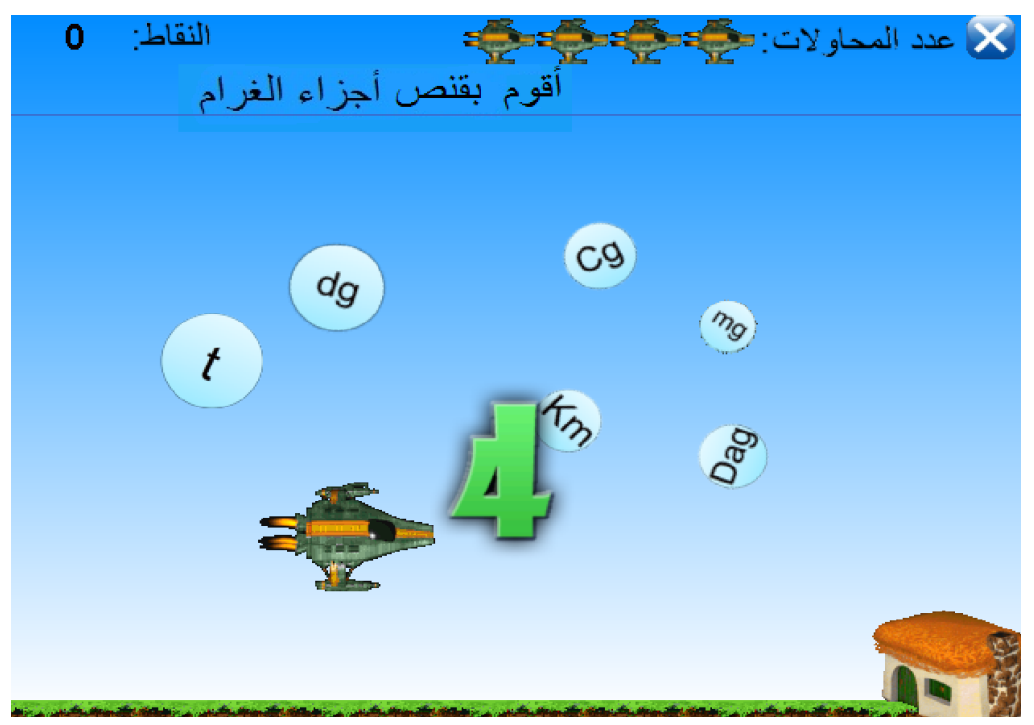

Fig. 7. Measure Game scene view

\section{$5 \quad$ Evaluation Results}

The number of students' who participated in this experience was 60 of an age between 10 and 11 years old. Students participate in a pre-test and post-test to identify the learning impact of JEUTICE before and after the game sessions. During two weeks, teacher explained game rules, avatar control, the score, number of lives concept, Feedbacks, and the implemented the mathematics achievement pre-test. Then for one-week (120 minutes) students experiment JEUTICE game. The purpose is to let students improve the learning motivation with a competitive interaction.

After the completing the game manipulation a simple and targeted survey is performed to evaluate the user's perceptions towards the game. Students express their degree of satisfaction during the game experience by answering a simple and questions on a scale of 1 to 7 . Thanks to this survey, we were able to learn more about the perspective of players perception towards JEUTICE game.

For the first tree questions, investigates the players feeling towards colors, avatar and the game environment. all the questions take as indicated answers on a scale of 1 to 7. we calculate the average of the players answers and we illustrated the result of 60 students in figure 8. regarding the environment colors players average impression $(\mathrm{m}=$ 6.71) was high, that indicates a significant homogeneity of the colors chosen. the second question investigates the feeling of the player towards the game avatars, for a significant average result $(\mathrm{m}=6.25)$ which indicate a positive impact towards the chosen avatars. Concerning the environment, average obtained $(\mathrm{m}=5.64)$ indicate also a positive feeling of student toward the environment design. This survey was important to identify the impact of JEUTICE game elements towards the players and identifying changes that can be made in order to improve the players immersion and the game experience. 
Regarding the $4^{\text {th }}$ and the $5^{\text {th }}$ questions the results obtained show that the situations presented to the student was well chosen and understandable $(\mathrm{m}=5.79) 82 \%$ of the students answered this question positively and $81 \%$ of the students indicated that the manipulation of the avatar in the scene was easy to manage with an average respond of ( $\mathrm{m}$ $=5.72$ ).

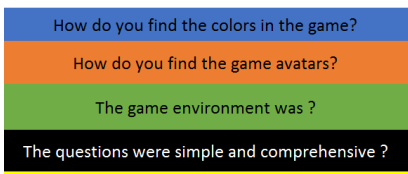

Did the avatar control was easy?

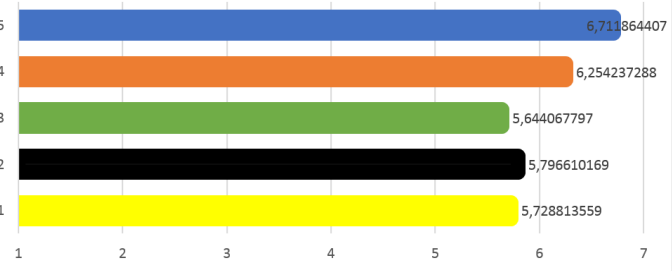

Fig. 8. Users perspectives results

Before starting the experiment, we must first identify players knowledge, in order to compare learning impact of JEUTICE on the students. We first identify the knowledge level of the students through a pretest noted in a scale of 0 to 10 according to the education ministry standard. Table 1 shows pretest result which present students' level of knowledge, of the three text book mathematics lessons. The questions that have been asked in pretest are about theoretical elements of measurements, surfaces and numbers. We noted that the participants in the group have slightly average overall results, with a large variance $(\mathrm{V} 1=3.68, \mathrm{~V} 2=2.26, \mathrm{~V} 3=3.57)$. and significant differences students' results are largely above or below from the average $(\mathrm{M} 1=7.05, \mathrm{M} 2=6.20, \mathrm{M} 3=6.21)$.

Table 1. Pretest result

\begin{tabular}{|c|c|c|c|c|}
\hline & Min & Max & Average & Variance \\
\hline Surfaces & 3 & 10 & 7.05 & 3.68 \\
\hline Measure & 3 & 10 & 6.20 & 2.46 \\
\hline Numbers & 3 & 10 & 6.21 & 3.57 \\
\hline
\end{tabular}

Table 2 shows the average scores obtained after play sessions (120min). the average score obtained for the tree games was important $(\mathrm{m}>74)$ with a small variance respectively of $(\mathrm{V} 1=12.26, \mathrm{~V} 2=15.91, \mathrm{~V} 3=8.76)$ taking in account that the standard of scores that we set for each game increases by 10 points for each positive transition. We can thus conclude that the level of knowledge in mathematics of the participants was good and relatively presented situations by JEUTICE to the participants was simple and comprehensive. Some students have expressed lack feeling based on idea on errors in the use of the workstation. Some students also expressed that they would not be able to keep up with the movement of balls that contains the answers. 
Table 2. Game score result

\begin{tabular}{|c|c|c|c|c|}
\hline & Min & Max & Average & Variance \\
\hline Surfaces score & 60 & 100 & 78.82 & 12.26 \\
\hline Measure score & 50 & 100 & 74.03 & 15.93 \\
\hline Numbers score & 70 & 100 & 84.67 & 8.76 \\
\hline
\end{tabular}

Participants were then asked to answers to a post-test after the JEUTICE experience. Table 3 shows the averages notes. The results obtained (Table 3) are positive. Most of the students had scores higher than the minimum required, this is well seen from then the minimum obtained respectively $(\operatorname{Min} 1=5, \operatorname{Min} 2=5, \operatorname{Min} 3=4)$ and a significant decrease in the variance of the student group compared to that obtained before the experiment $(\mathrm{V} 1=1.20, \mathrm{~V} 2=1, \mathrm{~V} 3=1.25)$.

Table 3. Post test result

\begin{tabular}{|c|c|c|c|c|}
\hline & Min & Max & Average & Variance \\
\hline Surfaces & 5 & 10 & 7.82 & 1.20 \\
\hline Measure & 5 & 10 & 7.13 & 1.00 \\
\hline Numbers & 4 & 10 & 7.29 & 1.25 \\
\hline
\end{tabular}

\section{Discussion}

The goodness of students' learning achievements is generally measured by paper and pencil tests. The types of mathematics topics that students are most likely to contact include multiple-choice questions, fill-in questions, and application questions. the paper and pencil test are generally recognized as a fast and effective evaluation method. Therefore, in the teaching methods, teaching content or teaching materials, and the provision of auxiliary equipment, it is necessary to adjust, adapt or adopt alternatives serious game in order to smoothly carry out teaching [28], and then cultivate their interest and confidence in learning, increase engagement and develop their learning potential. JEUTICE mathematics games should be a good solution to this problem, this conclusion verified through an in the class group mathematics experiment teaching program, students with mathematics learning difficulties participate in the game activities, to track the learning process and students feeling towards JEUTICE game. From figure 8 it can be seen that after the implementation of JEUTICE the student's interest gained from the benefits of the perspective designed environment, ease of avatar control and adaptative questions given the students a positive impact and psychological satisfaction. From the Table 1 and Table 3, before and after the implementation of JEUTICE game the result obtained from pre-test and post-test shows the learning achievement which did reach a statistically significant level. The great difference between variance respectively for the post test $(\mathrm{V} 1=1, \mathrm{~V} 2=1, \mathrm{~V} 3=1.25)$ compared to variance obtained from the pre-test $(\mathrm{V} 1=3.68, \mathrm{~V} 2=2.46, \mathrm{~V} 3=3.57)$ indicate that differences between learners have been greatly reduced. It can be seen that JEUTICE stimulate the student's interest and engagement to solve mathematics problem although it improves students' mathematics 
learning achievements. Therefore, students try many new behaviors from the game and different ways of playing connecting these playing strategies to their real-life situations, and then solve the problems. From Table 2 and comparing score results to pretest we can notice that JEUTICE stimulate students' interest and motivation, help students to establish students' thinking ability, and help students to master mathematics basic skills, computing skills, as well as building self-confidence, leveraging teaching and improving overall learning outcomes. pointed out that mathematics learning difficulties occur among 3\% to $8 \%$ of ordinary Belgium students [21], the number of mathematics learning disabilities increases with grades [22]. Taking into account that there are no similar study and without effective intervention, this mathematical learning difficulty (learning low achievement) will continue to exist in Moroccan primary school, leading to low interest and fear of mathematics. Therefore, if teachers can combine the characteristics of JEUTICE game, and integrate into the mathematics learning of the neediest students and letting the teachers choose the appropriate units or time slots to implement the teaching through the active game teaching method. Students with obstacles like mathematics are willing to think and solve problems in practical way.

\section{Conclusion}

Most of the children come to school their favorite activity is to play with their classmates. As for the mathematics study, there is a lack of interest [23]. Most of the students have a fear of mathematics, and mathematics is also passive in school [24]. Therefore, from gamified mathematics lessons and through appropriate diversified assessments activities. This study found that the integration of JEUTICE games into teaching activities give great help to enhance students' interest in mathematics learning. Students learning in games is a stress-free learning activity. If students are interested in mathematics, they can cause learning motivation, and then generate learning motivation, and gradually achieve the learning effect. In the current teaching environment, teachers mostly use competencies teaching method. Although, students are mostly lack of interest in mathematics learning. If teachers can properly use the flexible time in the curriculum to integrate into the group, they will promote students' interest in learning. The content and methods of JEUTICE games are related student's textbook.

\section{Acknowledgement}

We are immensely grateful to the pedagogical team of Abdellah Guennoun primary school for their support during JEUTICE tests.

\section{References}

[1] Van Broeckhoven, F., Vlieghe, J., \& De Troyer, O. (2015, September). Mapping between pedagogical design strategies and serious game narratives. In 2015 7th International Conference on Games and Virtual Worlds for Serious Applications (VS-Games) (pp. 1-8). IEEE. https://doi.org/10.1109/vs-games.2015.7295780 
[2] DomíNguez, A., Saenz-De-Navarrete, J., De-Marcos, L., FernáNdez-Sanz, L., PagéS, C., \& MartíNez-3HerráIz, J. J. (2013). Gamifying learning experiences: Practical implications and outcomes. Computers \& Education, 63, 380-392. https://doi.org/10.1016/j.co mpedu.2012.12.020

[3] Pannese, L., \& Carlesi, M. (2007). Games and learning come together to maximise effectiveness: The challenge of bridging the gap. British Journal of Educational Technology, 38(3), 438-454. http://dx.doi.org/10.1111/j.1467-8535.2007.00708.x.

[4] Meluso, A., Zheng, M., Spires, H. A., \& Lester, J. (2012). Enhancing 5th graders' science content knowledge and self-efficacy through game-based learning. Computers \& Education, 59(2), 497-504. http://dx.doi.org/10.1016/j.compedu.2011.12.019.

[5] Van Eck, R. (2007). Building artificially intelligent learning games. In Games and simulations in online learning: Research and development frameworks (pp. 271-307). IGI Global. http://dx.doi.org/10.4018/978-1-59904-304-3.ch014.

[6] Reinders, H., \& Wattana, S. (2015). Affect and willingness to communicate in digital gamebased learning. ReCALL, 27(1), 38-57. http://dx.doi.org/10.1017/S0958344014000226.

[7] Simões, J., Redondo, R. D., \& Vilas, A. F. (2013). A social gamification framework for a K-6 learning platform. Computers in Human Behavior, 29(2), 345-353. http://dx.doi.org/10.1016/j.chb.2012.06.007.

[8] Jiang, J., Phalp, K. T., \& Ali, R. (2015). Digital addiction: Gamification for precautionary and recovery requirements.

[9] Lewis, Z. H., Swartz, M. C., \& Lyons, E. J. (2016). What's the point? a review of reward systems implemented in gamification interventions. Games for health journal, 5(2), 93-99. http://dx.doi.org/10.1089/g4h.2015.0078.

[10] Arnab, S., Lim, T., Carvalho, M. B., Bellotti, F., De Freitas, S., Louchart, S., ... \& De Gloria, A. (2015). Mapping learning and game mechanics for serious games analysis. British Journal of Educational Technology, 46(2), 391-411. http://dx.doi.org/10.1111/bjet.12113.

[11] Cagiltay, N. E., Ozcelik, E., \& Ozcelik, N. S. (2015). The effect of competition on learning in games. Computers \& Education, 87, 35-41. http://dx.doi.org/10.1016/j.compedu.2015. 04.001.

[12] Sepehr, S., \& Head, M. (2018). Understanding the role of competition in video gameplay satisfaction. Information \& Management, 55(4), 407-421. http://dx.doi.org/10.1016/j.im. 2017.09.007.

[13] Jean, S., Medema, W., Adamowski, J., Chew, C., Delaney, P., \& Wals, A. (2018). Serious games as a catalyst for boundary crossing, collaboration and knowledge co-creation in a watershed governance context. Journal of environmental management, 223, 1010-1022. http://dx.doi.org/10.1016/j.jenvman.2018.05.021.

[14] Tazouti, Y., Boulaknadel, S., \& Fakhri, Y. (2015, December). Enhancing young children's mathematics skills using serious game approach. In 2015 5th International Conference on Information \& Communication Technology and Accessibility (ICTA) (pp. 1-3). IEEE. http://dx.doi.org/10.1109/ICTA.2015.7426918.

[15] Al Khateeb, M. A. (2019). Effect of Mobile Gaming on Mathematical Achievement among 4th Graders. International Journal of Emerging Technologies in Learning, 14(7). https://doi.org/10.3991/ijet.v14i07.10315.

[16] Al-Razgan, M. S. (2017). Afaneen: The Design and Evaluation of an Interactive Mobile Game to Enhance Arabic Spelling. J. UCS, 23(12), 1172-1199. http://dx.doi.org/10. 3217/jucs-023-12-1172

[17] Salah, J., Abdennadher, S., Sabty, C., \& Abdelrahman, Y. (2016, September). Super alpha: Arabic alphabet learning serious game for children with learning disabilities. In Joint International Conference on Serious Games (pp. 104-115). Springer, Cham. https://doi.org/10. 1007/978-3-319-45841-0_9. https://doi.org/10.1007/978-3-319-45841-0_9 
[18] Sweidan, S. Z., \& Darabkh, K. A. (2018). VREG: A Virtual Reality Educational Game with Arabic Content Using Android Smart Phone. Journal of Software Engineering and Applications, 11, 500-520. http://dx.doi.org/10.4236/jsea.2018.1110030.

[19] Vandercruysse, S., ter Vrugte, J., de Jong, T., Wouters, P., van Oostendorp, H., Verschaffel, L., \& Elen, J. (2015). "Zeldenrust": A mathematical game-based learning environment for prevocational students. In Describing and studying domain-specific serious games (pp. 6381). Springer, Cham. https://doi.org/10.1007/978-3-319-20276-1 5

[20] Pellegrini, A. D., \& Smith, P. K. (1993). School recess: Implications for education and development. Review of educational research, 63(1), 51-67. http://dx.doi.org/10.3102/ 00346543063001051.

[21] Desoete, A., Roeyers, H., \& De Clercq, A. (2004). Children with mathematics learning disabilities in Belgium. Journal of learning disabilities, 37(1), 50-61. http://dx.doi.org/10. $1177 / 00222194040370010601$.

[22] Wei, X., Lenz, K. B., \& Blackorby, J. (2013). Math growth trajectories of students with disabilities: Disability category, gender, racial, and socioeconomic status differences from ages 7 to 17. Remedial and Special Education, 34(3), 154-165. http://dx.doi.org/10.1177/ 0741932512448253.

[23] Köller, O., Baumert, J., \& Schnabel, K. (2001). Does interest matter? The relationship between academic interest and achievement in mathematics. Journal for Research in Mathematics Education, 448-470.http://doi.org/10.2307/749801.

[24] Geist, E. (2010). The Anti-Anxiety Curriculum: Combating Math Anxiety in the Classroom. Journal of Instructional Psychology, 37(1).

\section{Authors}

Yassine Tazouti is a PhD student at the Laboratory for Research in computing and Telecommunication (LaRIT) faculty of science kénitra, Morocco. He was awarded a master of mathematics and information technology from Abdelmalek Essaadi university, Tetouan-Morocco in 2014.

Siham Boulaknadel is a researcher at the Royal Institute of Amazighe Culture, Associate Researcher at the Laboratory of Research in Computer Science and Telecommunications (LRIT) Faculty of Sciences of Rabat and Member of the Skill Pole STIC Morocco. His research interests include automatic language processing, information retrieval, artificial intelligence and distance learning.

Youssef Fakhri received his Bachelor's Degree (B.S) in Electronic Physics in 2001 and his Master's Degree (DESA) in Computer and Telecommunication from the Faculty of Sciences, University Mohammed V, Rabat, Morocco, in 2003 where he developed his Master's Project at the ICI Company, Morocco. He received a PhD in 2007 from the University Mohammed V - Agdal, Rabat, Morocco in collaboration with the Polytechnic University of Catalonia (UPC), Spain. He joined the Faculty of Sciences of Kénitra, Department of Computer Science and Mathematics, IbnTofail University, Morocco, as an Associate Professor in March 2009, he is the Laboratory head at LaRIT (Laboratory for Research in Computing and Telecommunication) in the Faculty of Kénitra, and Member of Pole of Competences STIC Morocco.

Article submitted 2019-06-25. Resubmitted 2019-08-01. Final acceptance 2019-09-14. Final version published as submitted by the authors. 